09

\title{
Одномодовый световод W-типа, устойчивый к изгибу и радиации
}

\author{
(C) М.А. Ероньян, ${ }^{1}$ А.Ю. Кулеш, ${ }^{1}$ А.А. Реуцкий, ${ }^{1}$ Д.Р. Деветьяров, ${ }^{1}$ И.С. Никитин, ${ }^{1}$ А.А. Унтилов, ${ }^{1}$ \\ Д.В. Волынский, ${ }^{1}$ И.А Овчинникова, ${ }^{2}$ Ю.К. Чаморовский, ${ }^{3}$ А.А. Печенкин ${ }^{4}$ \\ ${ }^{1}$ АО „Концерн „Центральный научно-исследовательский институт „Электроприбор“, \\ 197046 Санкт-Петербург, Россия \\ ${ }^{2}$ Всероссийский научно-исследовательский, проектно-конструкторский и технологический институт кабельной \\ промышленности, \\ 111024 Москва, Россия \\ ${ }^{3}$ Институт радиотехники и электроники им. В.А. Котельникова РАН, \\ 141190 Фрязино, Московская обл., Россия \\ ${ }^{4}$ Национальный исследовательский ядерный университет „МИФИ“, \\ 115409 Москва, Россия \\ e-mail: eronyan@mail.ru
}

Поступило в Редакцию15 фревраля 2020 г.

В окончательной редакции 20 апреля 2020 г.

Принято к публикации 20 апреля 2020 г.

Установлено, что одномодовые фторсиликатные волоконные световоды, изготавливаемые модифицированным методом химического парофазного осаждения, резко снижают радиационную стойкость при введении в сердцевину из кварцевого стекла $1 \mathrm{~mol} \% \mathrm{GeO}_{2}$. Устранением примесей хлора и ОН-групп из кварцевого стекла сердцевины фторсиликатного одномодового волоконного световода достигнут низкий уровень радиационно-наведенных оптических потерь. Затухание волоконного световода до радиационной обработки равно 0.18 и $0.3 \mathrm{~dB} / \mathrm{km}$ на длине волны 1.55 и $1.31 \mu \mathrm{m}$ соответственно. Исследована зависимость оптических потерь таких световодов от диаметра их изгиба в диапазоне 6-12 mm.

Ключевые слова: MCVD-метод, одномодовые световоды, фторсиликатная оболочка, оптические потери, радиационная стойкость.

DOI: $10.21883 /$ JTF.2020.12.50134.53-20

\section{Введение}

Потребность в радиационно-стойких волоконных световодах (РСВС), предназначенных для работы в условиях повышенного радиационного фона и особо низких температур, актуальна для целого ряда важных применений, в первую очередь для космической техники. В нашей стране Институты Российской академии наук ведут разработки таких волоконных световодов (ВС) не самым производительным, но универсальным методом MCVD (Modified chemical vapor deposition) [1]. Сердцевина РСВС состоит из чистого кварцевого стекла, а оболочка - из фторсиликатного стекла [2-4]. Изза многоступенчатого радиального профиля показателя преломления (ПП) они называются ВC W-типа.

От обычных ВС ступенчатого типа они отличаются тем, что излучение в них вытекает в наружную оболочку с повышенным ПП по сравнению с фторсиликатной оболочкой. Для практически полного исключения этого явления диаметр фторсиликатной оболочки одномодовых ВС должен не менее, чем в 8 раз, превышать диаметр сердцевины из чистого кварцевого стекла [5]. Незначительное увеличение ПП сердцевины за счет ее легирования $\mathrm{GeO}_{2}$ позволяет снизить это соотношение до 6 [6], что существенно (на 70\%) может сократить длительность процесса осаждения оболочки. О целесообразности введения диоксида германия в сердцевину РСВС свидетельствуют результаты работы [7], выявившей более высокую радиационную стойкость германосиликатных ВС в сравнении с фторсиликатными. Последующие исследования $[8,9]$ подтвердили высокую радиационную стойкость многомодовых германосиликатных ВС.

Другой отличительной особенностью фторсиликатных $\mathrm{BC}$, изготавливаемых MCVD-методом, является способ нанесения отражающей депрессированной оболочки. Она может формироваться одностадийным способом, когда осаждение частиц $\mathrm{SiO}_{2}$ на внутреннюю поверхность трубки, их спекание и легирование фтором происходят за один проход горелки [2]. Альтернативный, более сложный двухстадийный, способ нанесения оболочки осуществляется за два прохода горелки. На первом проходе она при осаждении слоя частиц $\mathrm{SiO}_{2}$ движется навстречу потоку парогазовой смеси, содержащей кислород и пары $\mathrm{SiCl}_{4}$. На втором проходе при спекании и фторировании пористого слоя горелка перемещается попутно с направлением подачи в трубку газообразного фторирующего реагента $\left(\mathrm{SiF}_{4}, \mathrm{SF}_{6}\right.$ и др.) [4].

$\mathrm{B}$ двухстадийном способе осаждения оболочки осаждаемые слои стекла содержат существенно меньше примесного хлора, чем в одностадийном способе. Этот элемент, наряду с примесными группами $\mathrm{OH}$, является основной причиной увеличения радиационнонаведенных оптических потерь (РНП) фторсиликатных ВС с сердцевиной из чистого кварцевого стекла [10]. 
Таблица 1. Параметры заготовок ВС

\begin{tabular}{c|c|c|c|c|c|c}
\hline $\begin{array}{c}\text { № } \\
\text { заготовки }\end{array}$ & $\begin{array}{c}\text { Диаметр оболочки } \\
\left(\mathrm{SiO}_{2}-\mathrm{F}\right), \mathrm{mm}\end{array}$ & $\begin{array}{c}\text { Диаметр } \\
\text { сердцевины, } \mathrm{mm}\end{array}$ & $\begin{array}{c}\text { Диаметр } \\
\text { заготовки, } \mathrm{mm}\end{array}$ & $\begin{array}{c}\text { Состав сердцевины } \\
\Delta n_{o}\end{array}$ & $\Delta n_{c}$ \\
\hline 1 & 8.0 & 1.0 & 17.4 & $0.99 \mathrm{SiO}_{2}-0.01 \mathrm{GeO}_{2}$ & -0.006 & +0.0015 \\
2 & 9.3 & 0.91 & 16.3 & $\mathrm{SiO}_{2}$ & -0.0095 & 0
\end{tabular}

Примечание. $\Delta n_{o}$ и $\Delta n_{c}$ - разность ПП фторсиликатной оболочки и сердцевины относительно наружной оболочки из чистого кварцевого стекла соответственно

В то же время присутствие 0.1 at.\% хлора в германосиликатном ВС почти в 10 раз снижает РНП [11].

Наилучшей радиационной стойкостью обладают фторсиликатные одномодовые ВС фирмы „Fujikura“ [12], производимые по сложной технологии, сочетающей VADи OVD-методы изготовления заготовок. Аналогичные изделия производит фирма „Draka “[13].

Изготавливаемые по более простой MCVD-технологии $[2,14,15]$ образцы фторсиликатных одномодовых РСВС Российской академии наук, не уступают по качеству аналогичным ВС зарубежных ведущих фирм. Высокий уровень радиационной стойкости в них достигается минимизацией содержания примесного хлора и созданием избытка кислорода при осаждении слоев сердцевины из чистого кварцевого стекла.

С утверждением о положительном влиянии избытка кислорода при осаждении слоев из чистого кварцевого стекла трудно согласиться, так как в одномодовом ВС концентрация кислорода и хлора в сердцевине определяется в основном условиями высокотемпературного сжатия трубки с осажденными слоями [16].

Изгиб ВС является эффективным инструментом в части ряда практических применений, когда их необходимо намотать на катушки датчиков малого диаметра. В этом отношении ВC W-типа более приемлемы, чем ВC с компенсированной по ПП оболочкой [17] из-за их осциллирующего характера ослабления излучения при его деформации [18]. Для ослабления таких осцилляций целесообразно использовать излучение коротковолнового края прозрачности кварцевых ВC $(1.31 \mu \mathrm{m})$ и повышать разность ПП сердцевины и оболочки.

Такая длина волны перспективна и для оптического кабеля дальней связи, так как она соответствует длине волны с нулевой дисперсией. Целью настоящей работы является исследование влияния на РНП при температуре $-60^{\circ} \mathrm{C}$ малых добавок $\mathrm{GeO}_{2}$ в сердцевину фторсиликатного одномодового ВС, изготавливаемого MCVD-методом, и влияния его изгиба на оптические потери на длине волны $1.31 \mu \mathrm{m}$.

\section{1. Методика эксперимента}

MCVD-методом на автоматизированном комплексе OFC-12-729 фирмы „Nextrom “ изготовлены две заготовки одномодовых ВC W-типа, на основе кварцевых труб из стекла марки F300 с наружным диаметром $25 \mathrm{~mm}$ и толщиной стенки $3 \mathrm{~mm}$. На рефрактометре Р-101 измерен радиальный профиль ПП заготовок и геометрические параметры их поперечного сечения (табл. 1). При изготовлении заготовки № 1 фторсиликатную оболочку наносили одностадийным методом, а для образца № 2 двухстадийным. Сердцевина заготовки № 1 легирована $\mathrm{GeO}_{2}$ на уровне $1 \mathrm{~mol} \%$, а сердцевина заготовки № 2 состояла из чистого кварцевого стекла.

Высокотемпературное сжатие заготовки проводили при температуре $2200-2250^{\circ} \mathrm{C}$ и продувке ее внутреннего канала газом, содержащим не более $10^{-6}$ wt.\% влаги. Длительность этой операции намеренно увеличили за счет повышенного противодавления внутри заготовки с целью более эффективного испарения хлора из слоя сердцевины. После сплавления внутреннего канала заготовки из нее вытягивали волокно диаметром $125 \mu \mathrm{m}$ при температуре графитового нагревателя $\approx 2150^{\circ} \mathrm{C}$ с одновременным нанесением защитного двухслойного эпоксиакрилатного УФ-отверждаемого защитно-упрочняющего покрытия толщиной $65 \mu \mathrm{m}$.

Оптические потери ВС определяли методом сравнения пропускания излучения для короткого и длинного (не менее $1000 \mathrm{~m}$ ) отрезков волокна с использованием анализатора оптического спектра марки „Yokogawa AQ6370C“،. Длину волны отсечки LP 11 моды измеряли на этом же приборе сопоставлением спектров пропускания на прямом и изогнутом отрезках РСВС. Зависимость оптических потерь $\left(\alpha_{b}\right)$ от диаметра изгиба волокна $(d)$ на $180^{\circ}$ исследовали на длине волны $1.31 \mu \mathrm{m} \mathrm{c} \mathrm{исполь-}$ зованием прибора „FOD-1208 Optical Tester“. Изменение диаметра изгиба волокна производили дискретно, с шагом в $1 \mathrm{~mm}$. Ошибка средней арифметической величины из трех измерений $\alpha_{b}$ составляла $5 \%$.

Исследование содержания фтора и хлора в поперечном срезе заготовок проводили на сканирующем электронном микроскопе „Jеol JSM-6480 LV“, снабженном спектрометром X-Max ${ }^{\mathrm{N}}$ (производство „Oxford Instruments“, Великобритания).

Исследование радиационной стойкости 100-метровых отрезков РСВС на длине волны $1.31 \mu \mathrm{m}$ при $(-60 \pm 5)^{\circ} \mathrm{C}$ проводили с использованием изотопного источника ${ }^{60} \mathrm{Co}$. Мощность дозы облучения величиной $1 \mathrm{~Gy} / \mathrm{s}$ достигалась расположением ВС на определенном расстоянии от источника излучения. Однородность поля радиационного воздействия была на уровне $20 \%$. Заданный уровень мощности дозы радиационной нагрузки 
достигался через 4 s. Снижение мощности (в $\mathrm{dB}$ ) проходящего по РСВС излучения в процессе облучения волокна регистрировали фотоприемником „Ophir PD300-IR“. Мощность зондирующего излучения на длине волны $1.31 \mu \mathrm{m}$ снижена до $5 \mu \mathrm{W}$, для минимизации фотообесцвечивания наведенных радиацией дефектов $[2,7]$. Регистрируемое прибором изменение РНП с ростом накопленной дозы в процессе облучения отличалось нестабильностью в пределах $\pm 5 \%$.

\section{2. Результаты и обсуждение}

Длина волны отсечки высшей моды $\mathrm{LP}_{11}\left(\lambda_{c}\right)$ для двух $\mathrm{BC}$ обеспечила одномодовый режим распространения излучения на длине волны 1.31 и $1.55 \mu \mathrm{m}$ с оптическими потерями $(\alpha)$ менее $0.5 \mathrm{~dB} / \mathrm{km}$. В сравнении с РСВС фирмы „Draka“ [13] BC № 1, легированный германием, незначительно уступает по затуханию на длине волны $1.31 \mu \mathrm{m}$, в то время как ВС № 2 имеет более низкие оптические потери как на длине волны $1.31 \mu \mathrm{m}$, так и при $1.55 \mu \mathrm{m}$ (табл. 2).

Измерение спектральной зависимости оптических потерь ВС № 2, обладающего более низким уровнем оптических потерь, выявило наличие примесных групп $\mathrm{OH}$. Величина пика оптического поглощения на длине волны $1.38 \mu \mathrm{m}$, равная $2 \mathrm{~dB} / \mathrm{km}$ (рис. 1 ), свидетельствует о содержании этой примеси менее $10^{-5}$ wt.\%.

Результаты исследования примесного состава слоев заготовки рентгеновским микрозондовым анализом показали, что при одностадийном способе нанесения фторсиликатной оболочки (заготовка № 1) содержание в ней хлора достигает 0.08 at.\%, а в сердцевине не превышает 0.05 at.\%. В заготовке № 2 при двухстадийном процессе формирования такой оболочки концентрация хлора как в оболочке, так и в сердцевине не превышает 0.02 at.\%.

Результаты измерения РНП ВС (рис. 2) показали, что введение даже малой добавки $\mathrm{GeO}_{2}$ в сердцевину приводит к резкому снижению радиационной стойкости. Оказалось, что в отличие от многомодовых германосиликатных $\mathrm{BC}$ [7] радиационная стойкость одномодовых оптических волокон существенно хуже, чем у фторсиликатных, а наличие примесного хлора не способствует их радиационной стойкости как в случае многомодовых ВС [11]. Здесь тем не менее следует отметить, что радиационная стойкость одномодовых ВС с германосиликатной сердцевиной существенно зависит

Таблица 2. Параметры РСВС

\begin{tabular}{c|c|c|c}
\hline BC & $\lambda_{v}, \mu \mathrm{m}$ & $\begin{array}{c}\alpha, \mathrm{dB} / \mathrm{km}, \\
\lambda=1.31 \mu \mathrm{m}\end{array}$ & $\begin{array}{c}\alpha, \mathrm{dB} / \mathrm{km}, \\
\lambda=1.55 \mu \mathrm{m}\end{array}$ \\
\hline № 1 & 1.20 & 0.48 & 0.25 \\
№ 2 & 1.16 & 0.3 & 0.18 \\
Draka & $\leq 1.26$ & $\leq 0.4$ & $\leq 0.3$
\end{tabular}

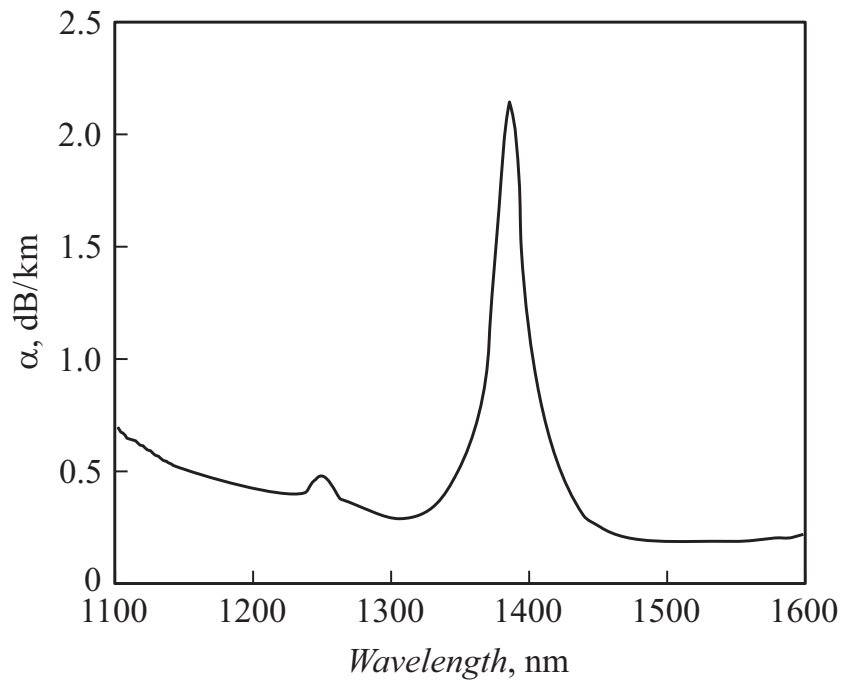

Рис. 1. Спектральная зависимость оптических потерь $(\alpha)$ для PCBC № 2.

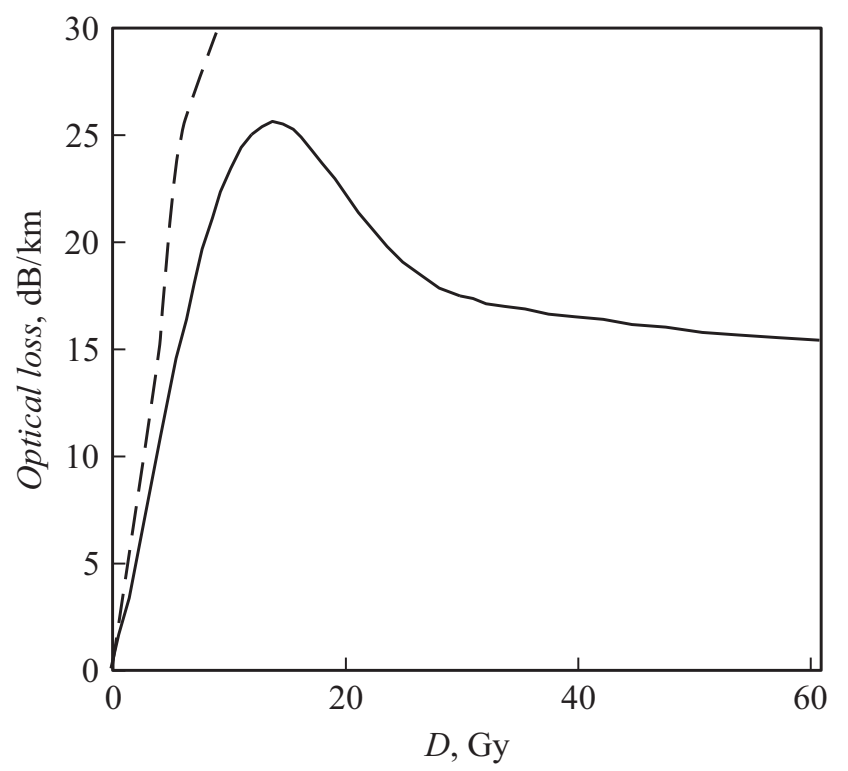

Рис. 2. Зависимость РНП (RIA) от дозы облучения $(D)$ для PCBC № 1 (штриховая линия) и № 2 (сплошная линия).

от типа отражающей оболочки. Так, использование фторсиликатной оболочки для таких световодов приводит к снижению РНП по сравнению с оболочкой из чистого кварцевого стекла [19].

РCВC № 1, легированный $\mathrm{GeO}_{2}$, в отличие от $\mathrm{BC}$ № 2 увеличивает РНП с повышением дозы облучения (рис. 2). Это обусловлено, вероятно, большим содержанием примесного хлора [15], который может инициировать образование малоизученных радиационных центров окраски $\mathrm{GeY}$ и $\mathrm{GeX}$.

Трехкратное снижение содержания германия в сердцевине ВС № 1 по сравнению с аналогом, содержащим $3.2 \mathrm{~mol} . \% \mathrm{GeO}_{2}$ [20] не оправдало надежды на 
повышение радиационной стойкости одномодовых ВС. Высокий уровень их РНП по сравнению с многомодовыми германосиликатными ВС [7] обусловлен, вероятно, дефицитом кислорода, возникающем в процессе высокотемпературного сжатия заготовки [16].

Малым содержанием хлора в РСВС № 2 обусловлены две особенности поведения РНП (рис. 2, 3), отмеченные в работе [21]:

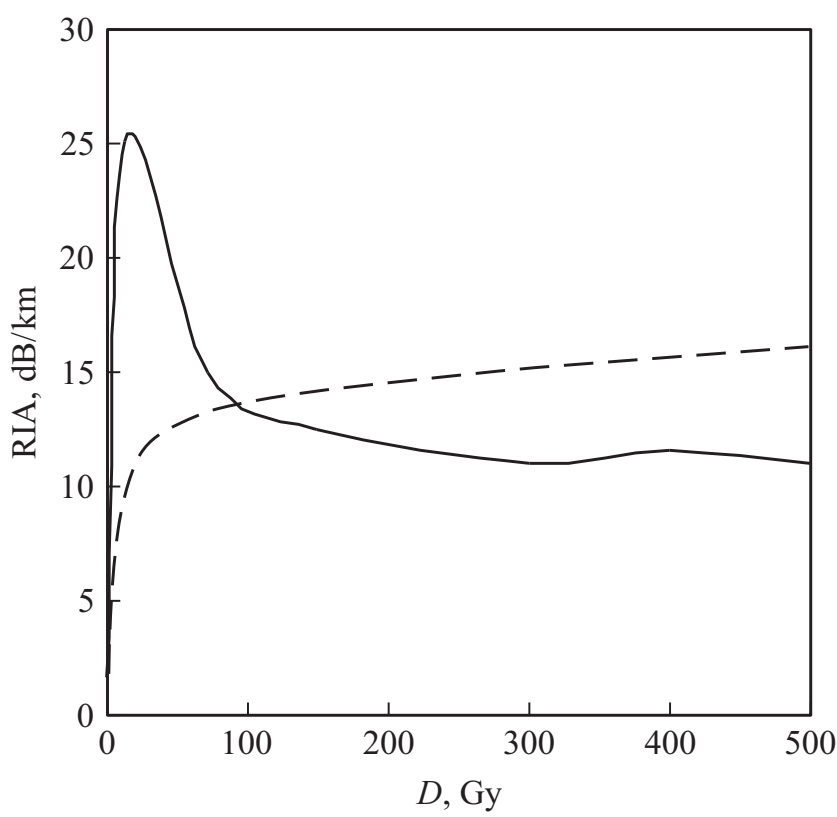

Pис. 3. Зависимость РНП (RIA) от дозы облучения $(D)$ для PCBC№ 2 (сплошная линия) и ВC фирмы „Draka“ (штриховая линия).

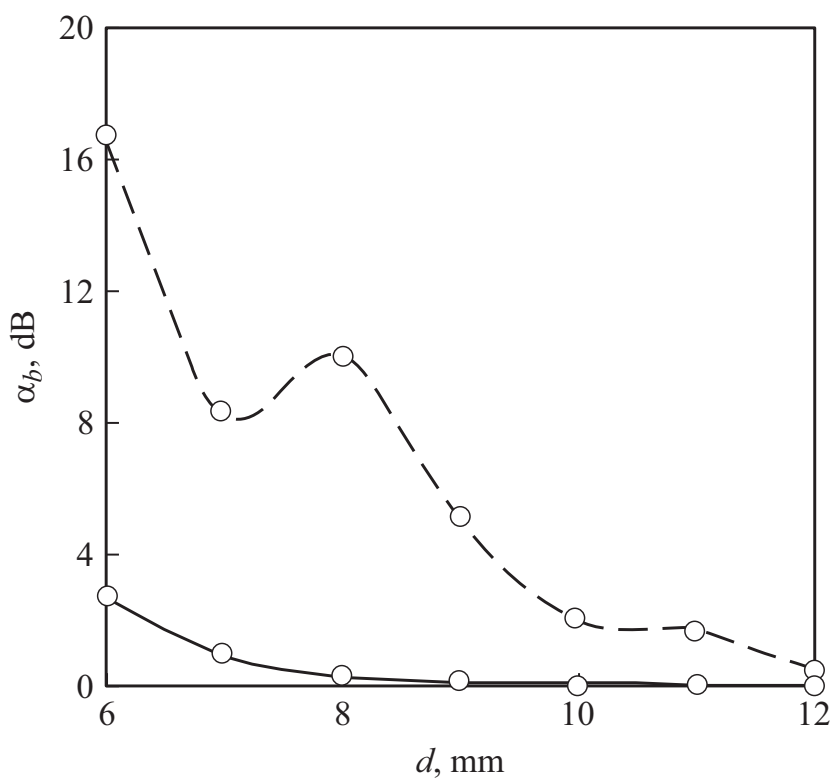

Рис. 4. Влияние диаметра $(d)$ изгиба волокна на оптические потери $\left(\alpha_{b}\right)$ при длине волны излучения $1.31 \mu \mathrm{m}$ для РСВС № 2 (сплошная линия) и SMF-28 (штриховая линия).

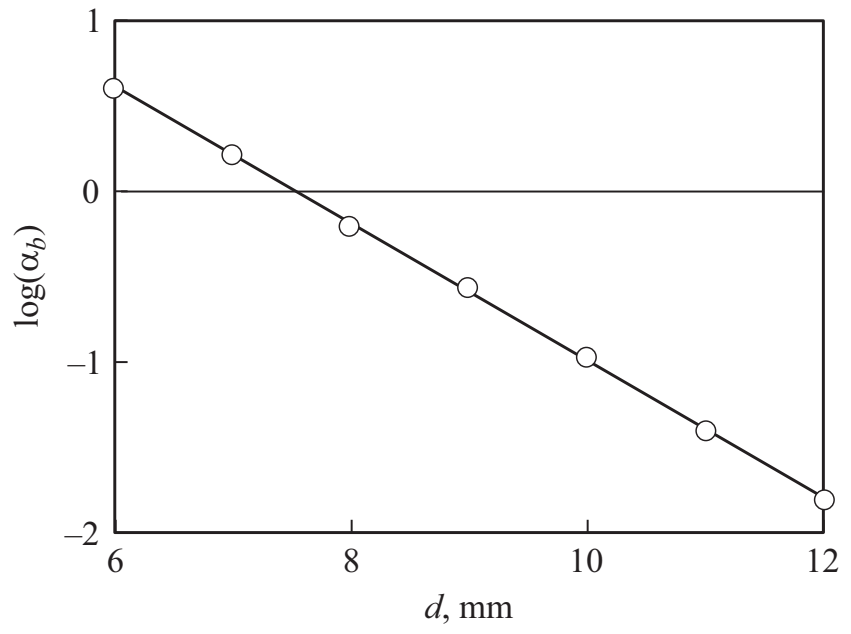

Рис. 5. Линейная аппроксимация экспериментальных данных (рис. 4) по влиянию изгиба волокна на оптические потери $\left(\alpha_{b}, \mathrm{~dB}\right)$ для РСВС № 2.

- резкое увеличение РНП до дозы гамма облучения $\approx 100 \mathrm{~Gy} \mathrm{и} \mathrm{последующий} \mathrm{спад;}$

- практически постоянный уровень РНП в процессе последующего гамма облучения в диапазоне доз $=100-500 \mathrm{~Gy}$.

Сопоставление характера изменения РНП с дозой облучения РСВС № 2 и аналогичного РСВС фирмы „Draka“ (рис. 3) может свидетельствовать о более низком уровне содержания примесного хлора в наших ВС.

Исследование устойчивости к изгибу проводили только для более перспективных по радиационной стойкости РСВС № 2 в сравнении с широко распространенным коммерческим одномодовым ВC типа SMF-28. Результаты измерений показали (рис. 4), что на длине волны $1.31 \mu \mathrm{m}$ РCВC № 2 в отличие от световода SMF-28 имеют монотонную зависимость изменения оптических потерь от диаметра изгиба и обеспечивают существенно более высокий уровень устойчивости к изгибу благодаря повышенному значению $\Delta n_{c}$.

Экспериментальные данные для РСВС № 2 в координатах $\log \left(\alpha_{b}\right)-d$ (рис. 5; $\log -$ десятичный логарифм) представляют линейную зависимость: $\log \left(\alpha_{b}\right)=4.5-0.375 d$.

Представленное уравнение дает возможность оценить оптические потери нашего РСВС при намотке на катушки малого диаметра. Так, 100 витков такого ВС на диаметре $25 \mathrm{~mm}$ приведет к увеличению оптических потерь на $0.0027 \mathrm{~dB}$.

\section{Заключение}

Результаты проведенных исследований свидетельствуют о том, что для германосиликатных одномодовых ВС в отличие от опубликованных данных для многомодовых, изготавливаемых MCVD-методом, ионизирующее 
излучение приводит к существенно более высокому уровню РНП. Введение в сердцевину из чистого кварцевого стекла фторсиликатных одномодовых ВС даже малых количеств $\mathrm{GeO}_{2}$ (не более 1 mol.\%) изменяет как количественно, так и качественно динамику роста РНП, увеличивающихся монотонно с дозой облучения. Экспериментальные образцы одномодовых фторсиликатных ВC W-типа с сердцевиной из кварцевого стекла, содержащего примесь ОН групп $\leq 10^{-5}$ wt.\%, обладают высоким уровнем оптической устойчивости как при радиационном воздействии, так и при изгибе волокна.

\section{Благодарности}

Авторы выражают признательность начальнику отдела $\mathrm{AO}$ „НПО ГОИ им. С.И. Вавилова“ Демидову В.В. за измерения радиального профиля показателя преломления заготовок и сотрудникам АО „Концерн „ ЦНИИ „Электроприбор“ Литуненко Е.Г. и Старцевой А.В. за исследования световодов методами электронной микроскопии.

\section{Конфликт интересов}

Авторы заявляют, что у них нет конфликта интересов.

\section{Список литературы}

[1] S.R. Nagel, J.B. MacChesney, K.L. Walker. IEEE J. Quant. Electron., 18 (4), 459 (1982).

[2] В.А. Аксенов, В.В. Волошин, И.Л. Воробьев, И.И. Долгов, Г.А. Иванов, В.А. Исаев, А.О. Колосовский, С.К. Моршнев, Ю.К. Чаморовский, М.Я. Яковлев. Радиотехника, 12, 51 (2005).

[3] A.L. Tomashuk, M.Yu. Salgansky, P.F. Kashaykin, V.F. Khopin, A.I. Sultangulova, K.N. Nishchev, S.E. Borisovsky, A.N. Guryanov, E.M.J. Dianov. Lightw. Technol., 32 (2), 213 (2014).

[4] А.Н. Гурьянов, М.Ю. Салганский, В.Ф. Хопин, А.Ф. Косолапов, С.Л. Семенов. Неорганические материалы, 45 (7), 881 (2009). [A.N. Guryanov, M.Yu. Salganskii, V.F. Khopin, A.F. Kosolapov, S.L. Semenov. Inorg. Mater. 45 (7), 823 (2009). DOI:10.1134/S0020168509070218]

[5] L.G. Cohen, D.M. Marcuse, W.L. Mammel. IEEE J. Quant. Electron., QE-18 (10), 1467 (1982).

[6] S.R. Nagel. J. Lightw. Technol. TL-2 (6), 213 (1984).

[7] K. Sanada, T. Shamoto, K.J. Inada. Non-Cryst. Solids, 189, 283 (1995).

[8] S. Girard, J. Keurinck, A. Boukenter, J.-P. Meunier, J. Ouerdane, B. Azais, P. Charre, M. Vie. Nucl. Instrum. Methods in Physics Research Section B: Beam Interactions with Materials and Atoms, 215 (1-2), 187 (2004).

[9] J. Bisutti, S. Girard, J. Baggio. J. Non-Cryst. Solids, 353, 461 (2007).

[10] K. Nagasawa, M. Tanabe, K. Yahagi. Jpn. J. Appl. Phys., 23, 1608 (1984).

[11] S. Shibata, M. Nakahara. J. Lightw. Technol., LT-3 (4), 860 (1985).
[12] K. Aikawa, K. Izoe, N. Shamoto, M. Kudoh, T. Tsumanuma. Fujikura Tech. Rev., 37, 9 (2008).

[13] Электронный ресурс. Режим доступа: www.draka.com/communications.com

[14] P.F. Kashaykin, A.L. Tomashuk, M.Yu. Salgansky, A.N. Abramov, R.N Nishchev, A.N. Guryanov, E.M.J. Dianov. Lightw. Technol., 33 (9), 1788 (2015).

[15] Д.А. Дворецкий, В.А. Лазарев, А.Б. Пнев, В.Е. Карасик, М.Ю. Салганский, П.Ф. Кашайкин, В.Ф. Хопин, А.Н. Гурьянов, Е.М. Дианов. Вестник МГТУ им. Н.Э. Баумана. Сер. Приборостроение, 5, 111 (2016). DOI: $10.18698 / 0236-3933-2016-5-111-124$

[16] А.Н. Гурьянов, Е.М. Дианов, С.В. Лаврищев, С.М. Мазавин, В.М. Машинский, В.Б. Неуструев, Н.И. Соколов, В.Ф. Хопин. Физика и химия стекла, 12 (3), 359 (1986).

[17] A.T. Andreev, A.B. Grudinin, E.M. Dianov, A.M. Prokhorov, A.N. Guryanov, G.G. Devjatykh, S.V. Ignatjev, V.F. Hopin. Electron. Lett., 17 (12), 416 (1981).

[18] P. Wang, Q. Wang, G. Farrell. Microwave Opt. Technol. Lett., 49 (9), 2133 (2007).

[19] S. Ju, P.R. Watekar, Y.-T. Ryu, Y. Lee, S.G. Kang, Y. Kim, K. Lingann, Y.H. Kim, W.-T. Han. Fiber Integrated Opt., 38 (4), 191 (2019). DOI: 10.1080/01468030.2019.1598520

[20] П.Ф. Кашайкин, А.Л. Томашук, М.Ю. Салганский, И.С. Азанова, М.К. Цибиногина, Т.В. Димакова, А.Н. Гурьянов, Е.М. Дианов. ЖТФ, 89 (5), 752 (2019). DOI: $10.21883 /$ JTF.2019.05.47480.123-18

[21] A.L. Tomashuk, E.M. Dianov, K.M. Golant, R.R. Khrapko, D.E. Spinov. IEEE Trans. Nucl. Sci., 45 (3), 1566 (1998). 